The ophthalmoscope was barely four years old in the Spring of 1855 , when the most celebrated case of persistent vomiting in pregnancy in history died on March 31. IVe refer to Charlotte Brontë. In the life by Mrs. Gaskell no reference is made to any complaint of visual loss and, with such an acute observer as Charlotte Brontë, we think she would most certainly have complained of not being able to see if there had been any very great loss of vision, so we suppose that these complications do not always occur. It is to be hoped that ophthalmic surgeons as well as obstetricians will read Professor Ballantyne's paper as well as that of $\mathrm{Mr}$. George Black in the present issue.

\title{
Prevention of Blindness in Bengal
}

The Tenth Annual Report of the Association for the Prevention of Blindness, Bengal, 1939-40, follows closely on the lines of the previous annual report, noticed in our columns, Vol. XXIV, p. 534.

The census returns of 1931 show 37,399 totally blind in Bengal and for every person blind there are three partially blind. Actual counts of the blind in villages are now being carried out and to date the numbers of the blind in 400 villages are known. These counts are carried out by trained ophthalmologists and when complete will be of the greatest value to the Association. Education of the Indian peasant is concerned with the evils of dirt, sepsis, quacks and the essentials of good diet, the proper cleansing of the eyes, the importance of vaccination against small-pox and the paramount importance of the preventative methods against ophthalmia neonatorum.

The Committee, of which Mr. Justice Henderson is the President and Lieut.-Colonel E. O'G. Kirwan, C.I.E. and S. K. Mukerjee are Hon. Secretaries, has been able to carry out most of the programme set for the Association at its first meeting in 1930. But, in spite of repeated recommendations the legislature has so far taken no action with regard to such subjects as compulsory vaccination, notification of venereal disease, regulations against adulteration of food and drink, unauthorised practitioners and quacks, prophylaxis against eye disease amongst the new-born, and indiscriminate advertisements by unauthorised practitioners.

The third and fourth travelling eye dispensaries, foreshadowed in the last report, came into being in February and March, 1940 respectively, and it is hoped that the fifth travelling dispensary will come into action this year.

The report is illustrated by reproductions of the various posters used in propaganda work and other photographs with details of the finances of the Association. 